Article

\title{
Rationale on the High Radical Scavenging Capacity of Betalains
}

\author{
Karina K. Nakashima ${ }^{+}(\mathbb{D})$ and Erick L. Bastos *(D) \\ Departamento de Química Fundamental, Instituto de Química, Universidade de São Paulo, \\ São Paulo, SP 05508-000, Brazil \\ * Correspondence: elbastos@iq.usp.br \\ + Current address: Institute for Molecules and Materials, Radboud University, \\ 6525 XZ Nijmegen, The Netherlands.
}

Received: 17 June 2019; Accepted: 11 July 2019; Published: 13 July 2019

check for updates

\begin{abstract}
Betalains are water-soluble natural pigments of increasing importance as antioxidants for pharmaceutical use. Although non-phenolic betalains have lower capacity to scavenge radicals compared to their phenolic analogues, both classes perform well as antioxidants and anti-inflammatory agents in vivo. Here we show that meta-hydroxyphenyl betalain ( $m$-OH-pBeet) and phenylbetalain (pBeet) show higher radical scavenging capacity compared to their $N$-methyl iminium analogues, in which proton-coupled electron transfer (PCET) from the imine nitrogen atom is precluded. The 1,7-diazaheptamethinium system was found to be essential for the high radical scavenging capacity of betalains and concerted PCET is the most thermodynamically favorable pathway for their one-electron oxidation. The results provide useful insights for the design of nature-derived redox mediators based on the betalain scaffold.
\end{abstract}

Keywords: betalain; antioxidant; radical scavenger; natural pigments; redox mediator

\section{Introduction}

Oxidants play a major role in metabolism [1-3]. Despite their importance in several biological processes, such as cell signaling, proliferation and differentiation, the overproduction of oxidants has been linked to harmful health effects [4]. The interpretation of scientific data for the action of oxygen, nitrogen and sulfur oxidants in vivo has changed over the decades. For example, cell death caused by oxidative stress is now considered-in certain cases-as an oxidant-triggered physiological process required to maintain physiological homeostasis rather than the root cause of all evil in biological systems [5].

Antioxidants have been considered to be must-use food supplements against the deleterious effects of oxidants [6,7]. This idea was broadly advertised in the second-half of the 20th century and echoes in the 21st century [8,9]. Natural products having high antioxidant capacity (thermodynamics, amount of radicals scavenged) and/or activity (kinetics, reactivity towards radicals) are high added value substances. However, several natural antioxidants can act as pro-oxidants, depending on the dose. Vitamin C and flavonoids, such as epicatechin gallate (ECG) from green tea, are examples of widely used antioxidants that show pro-oxidant action under certain conditions [10,11].

Betalains are chiral water-soluble natural products that replace anthocyanins in the pigmentation of most families of Caryophyllales plants [12-15]. Betanin (betanidin 5-O-glucoside) is a phenolic betalain found in beetroots (Beta vulgaris L.) that has been used as an U.S. Food and Drug Administration-approved food colorant additive [16]. The chemical versatility of betanin has led to its application as a redox mediator in dye-sensitized solar cells [17] and hydrogen production systems [18,19], for the synthesis of metal nanoparticles [20], as an anti-inflammatory agent [21], 
and as an antioxidant [22]. The antioxidant capacity of betanin is comparable to that of ECG due to the presence of a 5-O-glucosyl catechol moiety and a 1,7-diazaheptamethinium [23] system [24-26]. We have found that $\mathrm{N}$-(3-hydroxylphenyl)betalain ( $m$-OH-pBeet) is an adequate model to study the mechanism of antioxidant action of betanin because they share the same radical scavenging capacity [27]. Although the antioxidant action of $m$-OH-pBeet was rationalized in terms of proton-coupled electron transfer (PCET), the importance of the 1,7-diazaheptamethinium system for the antioxidant potential of betalains could not be elucidated [27].

Here we discriminate between the contributions of the phenolic moiety and the 1,7-diazaheptamethinium system on the antiradical properties of betalains and provide evidence that betalains undergo concerted PCET, transferring electrons and protons that are not necessarily at the same reaction site. The radical scavenging capacity, electrode potentials and electronic properties of phenyl betalain (pBeet) and $m$-OH-pBeet were compared to those of their corresponding $N$-methyl analogues, $\mathrm{N}$-methyl- $\mathrm{N}$-phenylbetalain (mepBeet) and $\mathrm{N}$-methyl- $\mathrm{N}$-(3-hydroxyphenyl)betalain ( $m$-OH-mepBeet), in which PCET involving the imino group is precluded. The presence of the $N$-methyl group attached to the imine nitrogen atom changes the charge delocalization profile of betalains, lowers the radical scavenging capacity, and increases the hydrolytic stability compared to the non-methylated analogues.

\section{Materials and Methods}

\subsection{General}

All chemicals were purchased from Sigma-Aldrich (Milwaukee, USA) and used without further purification, except as otherwise stated. Solutions were prepared using deionized water $(18.2 \mathrm{M} \Omega \mathrm{cm}$ at $25^{\circ} \mathrm{C}$, total organic carbon $\leq 4 \mathrm{ppb}$, Milli-Q, Millipore (Massachusetts, USA). Values are expressed as mean \pm standard deviation of three completely independent replicates.

\subsection{Semisynthesis of Betalains}

pBeet, mepBeet, $m$-OH-pBeet, and $m$-OH-mepBeet were semisynthesized using betalamic acid according to a procedure adapted from Schliemann and coauthors [28]. In a 5-mL one-necked round-bottom flask protected from light were placed a solution of betalamic acid $\left(1 \mathrm{mmol} \mathrm{L}^{-1}\right)$ in ethyl acetate $(2 \mathrm{~mL})$ and solid aminophenol (10 equivalents). The suspension was submitted to ultrasonic irradiation $\left(40 \mathrm{kHz}\right.$, bath) until the solid had dissolved, kept at $25^{\circ} \mathrm{C}$ for $30 \mathrm{~min}$, and the resulting solution was kept in a freezer $\left(-20 \pm 2{ }^{\circ} \mathrm{C}\right)$ overnight. The resulting suspension was centrifuged $\left(5000 \times g, 5{ }^{\circ} \mathrm{C}, 5 \mathrm{~min}\right)$ and the precipitate was washed twice with ethyl acetate. Products were purified through semi-preparative reversed phase HPLC/PDA (Phenomenex Luna C18 $25 \mathrm{~cm} \times 1 \mathrm{~cm}$, $5 \mu \mathrm{m}$, isocratic $20 \% \mathrm{~B}$; solvent systems, A: formic acid $(0.1 \% v / v)$ in water, B: formic acid $(0.1 \% v / v)$ in MeCN/water (90/10 v/v); flow rate: $3 \mathrm{~mL} \mathrm{~min}^{-1}$; monitoring at $254 \mathrm{~nm}, 400 \mathrm{~nm}$, and $500 \mathrm{~nm}$ ). Fractions containing betalains were combined, frozen and lyophilized. Products were kept in the dark at $-20{ }^{\circ} \mathrm{C}$ and submitted to UV-vis spectrophotometric analysis immediately before use. The average yield is $20 \%$.

pBeet; ${ }^{1} \mathrm{H}$ NMR $\left(500 \mathrm{MHz}\right.$, Methanol- $\left.d_{4}\right) \delta 8.50(\mathrm{~d}, J=12.0 \mathrm{~Hz}, 1 \mathrm{H}), 7.43(\mathrm{t}, J=7.7 \mathrm{~Hz}, 2 \mathrm{H}), 7.37$ $(\mathrm{d}, J=8.0 \mathrm{~Hz}, 2 \mathrm{H}), 7.25-7.19(\mathrm{~m}, 1 \mathrm{H}), 6.36(\mathrm{~s}, 1 \mathrm{H}), 6.21(\mathrm{~d}, J=12.0 \mathrm{~Hz}, 1 \mathrm{H}), 4.52(\mathrm{t}, J=7.4 \mathrm{~Hz}, 1 \mathrm{H}), 3.43$ $(\mathrm{dd}, J=17.5,7.4 \mathrm{~Hz}, 1 \mathrm{H}), 3.24(\mathrm{dd}, J=17.5,7.4 \mathrm{~Hz}, 1 \mathrm{H})$. HPLC-ESI(+)/MS: $\mathrm{R}_{\mathrm{t}}=6.2 \mathrm{~min}(\mathrm{see} S I), \mathrm{m} / \mathrm{z}$ 287.1. Magenta solid.

m-OH-pBeet; ${ }^{1} \mathrm{H}$ NMR (500 MHz, Methanol- $\left.d_{4}\right) \delta 8.35(\mathrm{bs}, 1 \mathrm{H}), 7.21(\mathrm{t}, J=8.1 \mathrm{~Hz}, 1 \mathrm{H}), 6.80(\mathrm{dd}$, $J=8.1,2.3 \mathrm{~Hz}, 1 \mathrm{H}), 6.75(\mathrm{t}, J=2.3 \mathrm{~Hz}, 1 \mathrm{H}), 6.64(\mathrm{dd}, J=8.1,2.3 \mathrm{~Hz}, 1 \mathrm{H}), 6.35(\mathrm{~s}, 1 \mathrm{H}), 6.15(\mathrm{~d}, J=12.7 \mathrm{~Hz}$, $1 \mathrm{H}), 4.44(\mathrm{t}, J=8.0 \mathrm{~Hz}, 1 \mathrm{H}), 3.24(\mathrm{dd}, J=17.9,8.0 \mathrm{~Hz}, 2 \mathrm{H})$. HPLC-ESI $(+) / \mathrm{MS}: \mathrm{R}_{\mathrm{t}}=4.7 \mathrm{~min}($ see $S I), \mathrm{m} / \mathrm{z}$ 303,1. Magenta solid. 
mepBeet; ${ }^{1} \mathrm{H}$ NMR (500 MHz, Methanol- $\left.d_{4}\right) \delta 8.18$ (bs, $\left.1 \mathrm{H}\right), 7.51(\mathrm{t}, J=8.0 \mathrm{~Hz}, 2 \mathrm{H}), 7.42(\mathrm{~d}$, $J=8.0 \mathrm{~Hz}, 2 \mathrm{H}), 7.38-7.32(\mathrm{~m}, 1 \mathrm{H}), 6.49(\mathrm{~s}, 1 \mathrm{H}), 6.14(\mathrm{bs}, 1 \mathrm{H}), 4.45(\mathrm{t}, J=7.8 \mathrm{~Hz}, 1 \mathrm{H}), 3.61(\mathrm{~s}, 3 \mathrm{H}), 3.20$ $(\mathrm{dd}, J=17.4,7.8 \mathrm{~Hz}, 1 \mathrm{H})$. HPLC-ESI(+)/MS: $\mathrm{R}_{\mathrm{t}}=6.7 \mathrm{~min}(\mathrm{see} S I), \mathrm{m} / z$ 301,2. Red solid.

m-OH-mepBeet; ${ }^{1} \mathrm{H}$ NMR $\left(500 \mathrm{MHz}\right.$, Methanol- $\left.d_{4}\right) \delta 8.15$ (bs, $\left.1 \mathrm{H}\right), 7.29(\mathrm{t}, J=8.1 \mathrm{~Hz}, 1 \mathrm{H}), 6.91-6.72$ $(\mathrm{m}, 3 \mathrm{H}), 6.48(\mathrm{~s}, 1 \mathrm{H}), 6.13(\mathrm{bs}, 1 \mathrm{H}), 4.46(\mathrm{t}, J=7.6 \mathrm{~Hz}, 1 \mathrm{H}), 3.57(\mathrm{~s}, 3 \mathrm{H}), 3.18(\mathrm{dd}, J=17.4,7.6 \mathrm{~Hz}, 1 \mathrm{H})$. HPLC-ESI(+)/MS: $\mathrm{R}_{\mathrm{t}}=5.4 \mathrm{~min}(\mathrm{see} S I), \mathrm{m} / \mathrm{z} 317,2$. Red solid.

\subsection{Radical Scavenging Capacity}

The Trolox Equivalent Antioxidant Capacity (TEAC) assay was used to determine the antiradical capacity of the betalains [29]. ABTS (2,2'-azinobis-(3-ethyl-benzothiazoline-6-sulfonic acid), $7 \mathrm{mmol} \mathrm{L}^{-1}$ ) was partially oxidized by potassium persulfate $\left(2.45 \mathrm{mmol} \mathrm{L}^{-1}\right)$ producing a solution of ABTS ${ }^{+\bullet} / \mathrm{ABTS}$ in water. The reaction was carried out in the dark at $25^{\circ} \mathrm{C}$ for $16 \mathrm{~h}$. The stock solution of ABTS ${ }^{+\bullet} / \mathrm{ABTS}$ was diluted to an absorbance of $0.7\left(46.7 \mu \mathrm{mol} \mathrm{L}{ }^{-1} \mathrm{ABTS}^{+\bullet}\right)$ at $734 \mathrm{~nm}$ using Britton-Robinson buffer (acetate/phosphate/borate, $0.4 \mathrm{~mol} \mathrm{~L}^{-1}$, at the different pHs). After addition of antioxidant (20-60 $\mu \mathrm{L}$, final concentration within the $\mu \mathrm{mol} \mathrm{L}{ }^{-1}$ range), changes in the absorbance at $734 \mathrm{~nm}$ were monitored for a period of 6 to $120 \mathrm{~min}(\Delta \mathrm{A})$. The antioxidant capacity is proportional to the slope of the linear correlation between $\Delta \mathrm{A}$ and the antioxidant concentration, $\alpha$. The TEAC is the $\alpha_{\text {sample }} / \alpha_{\text {Trolox }}$ ratio.

\subsection{Computational Methods}

The theoretical study of PCET was carried out using the Density Functional Theory (DFT)-optimized geometries of pBeet, mepBeet, $m$-OH-pBeet, and $m$-OH-mepBeet, their deprotonated forms (at N1-H, N9-H and $\mathrm{PhO}-\mathrm{H}$, when feasible), and the corresponding radical cations. All equilibrium geometries were optimized at the SMD(water)/M06-2X/6-311++G(d,p) level [30-32], and stationary points were characterized as minima based on vibrational analysis. The reported energies include the zero-point energy and thermal corrections ( $\mathrm{T}=298.15 \mathrm{~K}$ ) to electronic energies. Gaussian09 rev. D.01 program suite was used for all calculations [33]. Equations (1)-(5) were used to calculate the thermodynamic parameters governing the radical scavenging mechanism [34].

$$
\begin{gathered}
\text { (Bond dissociation enthalphy, BDE, BetH })=H\left(\operatorname{Bet}^{\bullet}\right)+H\left(\mathrm{H}^{\bullet}\right)-H(\operatorname{BetH}) \\
(\text { Ionization potential, IP, BetH })=H\left(\operatorname{BetH}^{+\bullet}\right)+H\left(\mathrm{e}^{-}\right)-H(\operatorname{BetH}) \\
\left(\text { Proton dissociation enthalpy, PDE, BetH }{ }^{+\bullet}\right)=H\left(\operatorname{Bet}^{\bullet}\right)+H\left(\mathrm{H}^{+}\right)-H\left(\operatorname{BetH}^{+\bullet}\right) \\
(\text { Proton affinity, PA, BetH })=H\left(\operatorname{Bet}^{-}\right)+H\left(\mathrm{H}^{+}\right)-H(\operatorname{BetH})
\end{gathered}
$$

(Electron transfer enthalpy, ETE, Bet $\left.{ }^{-}\right)=H\left(\operatorname{Bet}^{\bullet}\right)+H\left(\mathrm{e}^{-}\right)-H\left(\operatorname{Bet}^{-}\right)$

The gas phase enthalpies of the proton $\left(6.197 \mathrm{~kJ} \mathrm{~mol}^{-1}\right)$, electron $\left(3.146 \mathrm{~kJ} \mathrm{~mol}^{-1}\right)$ and hydrogen atom $\left(-1306 \mathrm{~kJ} \mathrm{~mol}^{-1}\right)$, as well as the solvation enthalpies (water) of the proton $\left(-1055.7 \mathrm{~kJ} \mathrm{~mol}^{-1}\right)$, electron $\left(-77.5 \mathrm{~kJ} \mathrm{~mol}^{-1}\right)$, and hydrogen atom $\left(-4 \mathrm{~kJ} \mathrm{~mol}^{-1}\right)$ were taken from the literature $[35,36]$. Phenol and the phenoxyl radical were used as reference compounds to calculate the $\triangle B D E^{\mathrm{PhOH}}$ (Equation (6)) [37].

$$
\Delta \mathrm{BDE}^{\mathrm{PhOH}}=H\left(\mathrm{Bet}^{\bullet}\right)+H(\mathrm{PhOH})-H(\operatorname{BetH})-H\left(\mathrm{PhO}^{\bullet}\right)
$$

The theoretical BDE of phenol at the SMD/M062X/6-311++G(d,p) level is $363.3 \mathrm{~kJ} \mathrm{~mol}^{-1}$ $\left(86.8 \mathrm{kcal} \mathrm{mol}^{-1}\right)$, which is in general agreement with the literature values of $86.7 \mathrm{kcal} \mathrm{mol}^{-1}$, $87.7 \mathrm{kcal} \mathrm{mol}^{-1}, 88.0 \pm 1 \mathrm{kcal} \mathrm{mol}^{-1}$, and $88.7 \mathrm{kcal} \mathrm{mol}^{-1}$ [38]. The values of BDE and bond dissociation free energy (BDFE) are expected to be similar since entropic changes are usually small for all-organic PCET reactions [38]. 


\section{Results and Discussion}

\subsection{Semisynthesis and Electronic Properties of pBeets and mepBeets}

Four model betalains were semisynthesized from betalamic acid (1) (extracted from hydrolyzed beetroot juice) and the anilines 2 using a scaled up procedure based on the method of Schliemann and coauthors [28] (Figure 1a). Ethyl acetate was used as the organic solvent [39] for both the extraction of 1 and the semisynthesis. The HPLC-DAD-MS/ESI(+) analysis and NMR spectra are presented in Figures S1-S8.

The absorption and fluorescence maximum wavelengths of the $N$-methyl betalains (mepBeets) in water are blue-shifted compared to those of pBeet and m-OH-pBeet (Table 1, Figure 1b). Consequently, mepBeets are orange (color data, CIE L 86 a -4 b 58), while the non-methylated analogues are bright salmon (CIE L 78 a 35 b 8). The color of pBeet was first described by Mabry and coauthors in the early 1970s when they performed seminal experiments coupling betalamic acid with amines and amino acids, and later by Gandía-Herrero and collaborators $[40,41]$. The fluorescence quantum yields $\left(\Phi_{\mathrm{FL}}\right)$ of mepBeets are ca. 30\% lower than those of pBeet and $m-\mathrm{OH}$-pBeet (Table 1), in agreement with reports on the effect of the presence of electron-donating substituents in the imine portion of aryl betalains [41-44]. Although pBeet is more fluorescent than the other three derivatives, i.e. 35\% more fluorescent than $m-\mathrm{OH}$-pBeet, it is still less emissive in solution than the natural betalain vulgaxanthin II $\left(\Phi_{\mathrm{FL}}\right.$ in water $\left.=7.3 \times 10^{-3}\right)[45]$.

${ }^{1} \mathrm{H}$ NMR data show that the $\mathrm{N}$-methyl group shields $\mathrm{H} 8$ and deshields $\mathrm{H} 5$ of these model betalains, possibly due to positive hyperconjugation $\left(\sigma^{2} \mathrm{CH} \rightarrow p_{\mathrm{N}}\right)$ [46] and because the aromatic ring and the 1,7-diazaheptamethinium group of the mepBeets are not coplanar (Figure 1c,d). The mepBeets show higher dipole moments $(\mu)$ compared to the pBeets, as evidenced by the increase of the positive charge density at N9 and decrease at N1 (Figure 1d). The greater charge localization of mepBeets explains their blue-shifted absorption spectra compared to pBeet and $m$-OH-pBeet, as well as the observed changes in the chemical shifts of $\mathrm{H} 8$ and $\mathrm{H} 5$.

$N$-Methyl betalains are more persistent in aqueous solution compared to pBeet and $m-\mathrm{OH}$-pBeet. The $\mathrm{pH}$ dependence of the observed rate constant for hydrolysis $\left(k_{\mathrm{obs}}\right)$ and the corresponding half-lives show the inverted bell-shaped profile typical of betalains (Figure 1e) [16]. Although all betalains show maximum persistence at $\mathrm{pH} 6$, the half-lives of mepBeets are roughly 25-times higher than those of pBeet and $m-\mathrm{OH}$-pBeet at $25^{\circ} \mathrm{C}$, i.e., $100 \mathrm{~h}$ vs. ca. $4 \mathrm{~h}$. The imine $s p^{2}$ carbons of non-methyl betalains are more activated towards nucleophilic attack by water and, consequently, hydrolyze faster than imino-protonated mepBeet and $m-\mathrm{OH}$-mepBeet. This result is important for the design of betalains that are less sensitive to hydrolysis, thus broadening the application of this class of compounds [47-49].

Table 1. Absorption and fluorescence properties of pBeets and mepBeets. ${ }^{\text {a }}$

\begin{tabular}{|c|c|c|c|c|c|c|}
\hline Compound & $\lambda^{\mathrm{abs}}(\mathrm{nm})$ & $\varepsilon^{b}$ & $\lambda^{\mathrm{EM}}(\mathrm{nm})$ & $\Delta \lambda\left(\mathrm{cm}^{-1}\right)$ & $\Phi_{\mathrm{Fl}}\left(/ 10^{-3}\right)^{\mathrm{c}}$ & $\mathrm{E}_{S}\left(\mathrm{~kJ} \mathrm{~mol}{ }^{-1}\right)$ \\
\hline pBeet & 508 & 61,300 & 558 & 1760 & $1.29 \pm 0.04$ & 220 \\
\hline mepBeet & 492 & 60,600 & 553 & 2240 & $0.56 \pm 0.04$ & 230 \\
\hline m-OH-pBeet & 508 & 64,000 & 563 & 1880 & $0.85 \pm 0.03$ & 220 \\
\hline m-OH-mepBeet & 492 & 60,500 & 550 & 2140 & $0.39 \pm 0.02$ & 230 \\
\hline
\end{tabular}

${ }^{a}$ In Britton-Robinson buffer (pH 6, $\left.40 \mathrm{mmol} \mathrm{L}^{-1}\right) ;{ }^{\mathrm{b}}$ In $\mathrm{L} \mathrm{mol}^{-1} \mathrm{~cm}^{-1}$, measured at $\mathrm{pH} 7$ (pBeets) or 11 (mepBeets).

${ }^{c}$ Using rhodamine B in ethanol as standard $\left(n_{\mathrm{D}}=1.3616 ; \Phi_{\mathrm{Fl}}=0.5\right)$ [52]. 

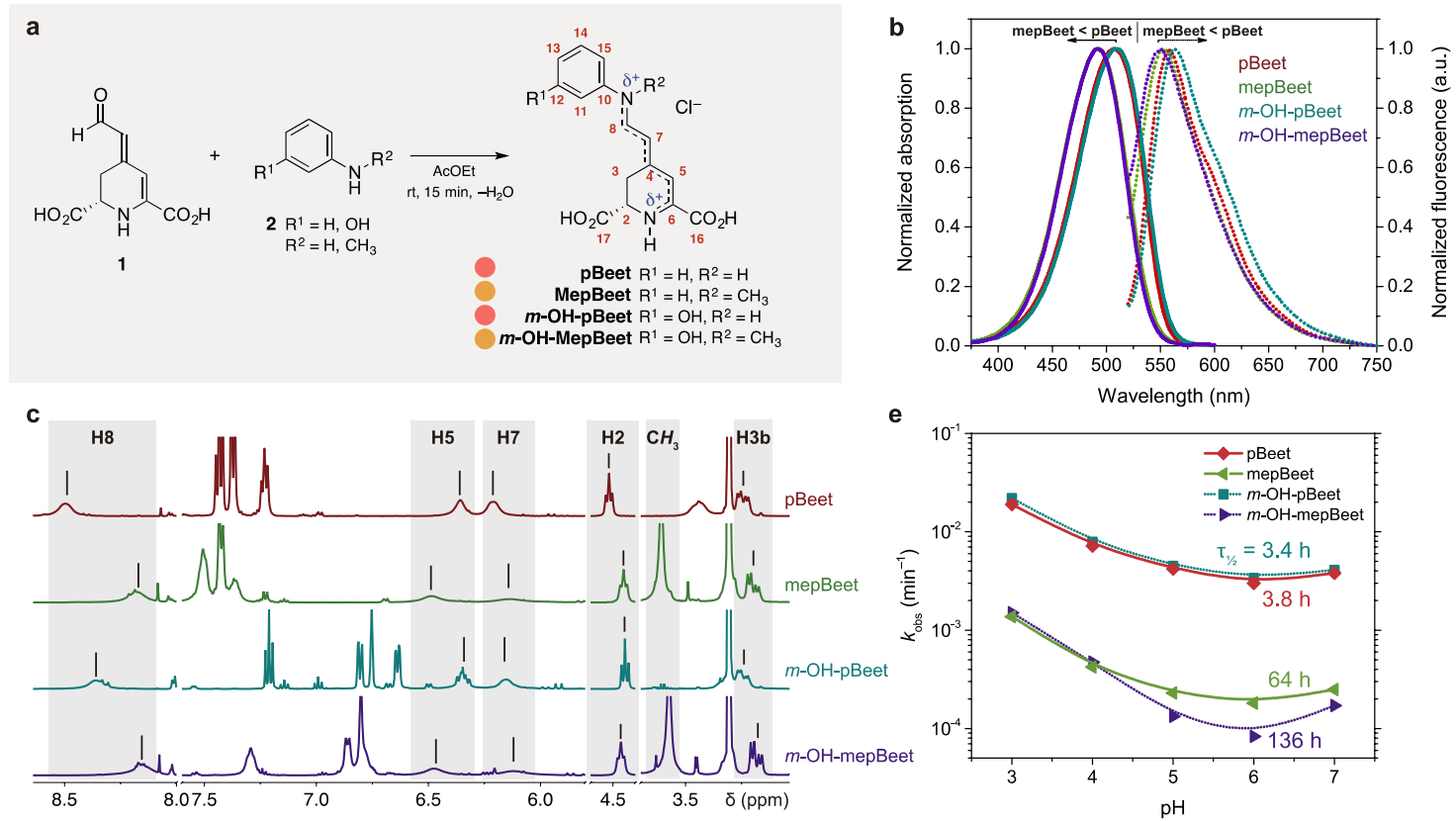

d
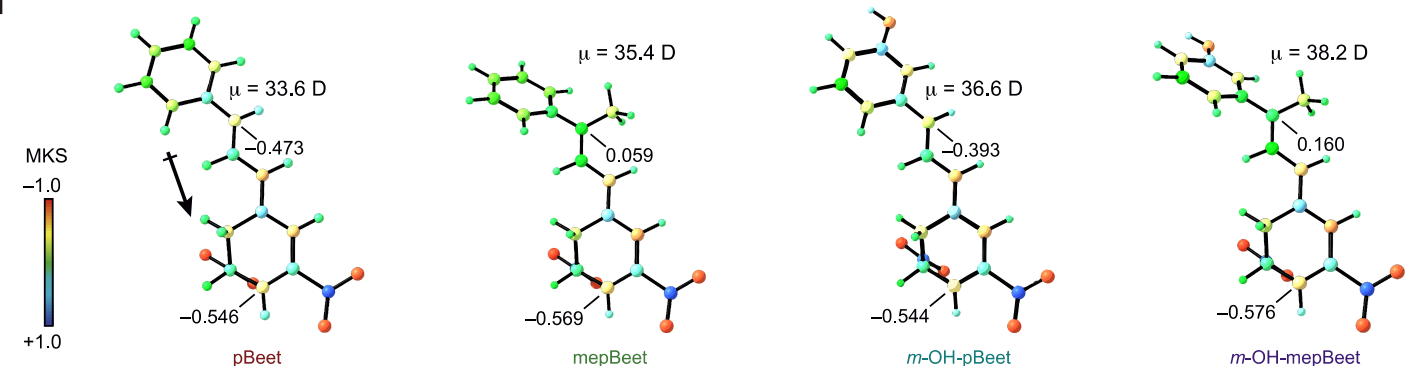

Figure 1. Semisynthesis and characterization of pBeets and mepBeets. (a) Acid-catalyzed coupling of betalamic acid (1) and anilines 2 in ethyl acetate. Atom numbering is shown in red and the colored circles indicate the color of each compound. (b) Normalized absorption (solid line) and fluorescence (dotted line) spectra of pBeets and mepBeets in BR buffer $\mathrm{pH}$ 6; excitation at $490 \mathrm{~nm}$. (c) ${ }^{1} \mathrm{H}$ NMR spectra of pBeets and mepBeets $\left(70 \mu \mathrm{mol} \mathrm{L}-1,500 \mathrm{MHz}, \mathrm{CD}_{3} \mathrm{OD}\right.$ at $\left.293 \mathrm{~K}\right)$. (d) Geometries of pBeets and mepBeets optimized at the SMD(water)/M06-2X/6-311++G(d,p) level and partial charges of the nitrogen atoms according to the Merz-Kollman-Singh (MKS) scheme constrained to reproduce the dipole moment $(\mu)$. The $\mathrm{p} K_{\mathrm{a}} \mathrm{s}$ of the carboxyl groups of betanin and indicaxanthin are ca. 3.5 [50,51] and, therefore, we show the carboxy-deprotonated forms of these model betalains. (e) Effect of $\mathrm{pH}$ on the observed rate constant $\left(k_{\mathrm{obs}}\right)$ and half-lives for the hydrolysis of the pBeets and the mepBeets at $\mathrm{pH} 6,25^{\circ} \mathrm{C}$.

\subsection{Radical Scavenging Capacity}

The radical scavenging capacity of pBeets and mepBeets was determined using the Trolox Equivalent Antioxidant Capacity (TEAC)/ABTS ${ }^{+\bullet}$ colorimetric assay [29]. In this assay, the reduction of the green-colored $\mathrm{ABTS}^{+\bullet}$ by antioxidants is quantified over a period of six minutes and the change in absorbance at $734 \mathrm{~nm}$ is used to calculate the TEAC value (see Methods). Since the reaction of ABTS ${ }^{+\bullet}$ with less reactive antioxidants may take more than $6 \mathrm{~min}$ to reach equilibrium [53], we monitored the reaction for up to $2 \mathrm{~h}$ at $\mathrm{pH}$ ranging from 3 to 7 . Results are presented as colored contour maps in Figure 2a. 
After $6 \mathrm{~min}$ in the presence of mepBeet or $m-\mathrm{OH}-\mathrm{mepBeet}$ under acidic conditions ( $\mathrm{pH}$ range 3-5), the concentration of $\mathrm{ABTS}^{+\bullet}$ increased, resulting in negative TEAC values and implying pro-oxidant action of $N$-methyl betalains (Figure $2 \mathrm{a}$, blue region, and Table S1). The ABTS ${ }^{+} \bullet$ solution contains residual ABTS, and may also contain traces of $\mathrm{ABTS}^{2+}$ formed by $2 \mathrm{e}^{-}$-oxidation of ABTS. The increase in ABTS $^{+\bullet}$ concentration caused by mepBeets can be explained by oxidation of ABTS and/or reduction of $\mathrm{ABTS}^{2+}$, whose absorption maxima are at 340 and $518 \mathrm{~nm}$, respectively. Although the absorption spectra of the betalains and $\mathrm{ABTS}^{+\bullet}$ do not superimpose, the spectrophotometric detection of ABTS and $\mathrm{ABTS}^{2+}$ is impossible due to the spectral overlap (Figure S9).

After ca. $30 \mathrm{~min}$, the TEAC of mepBeet and $m$-OH-mepBeet becomes positive due to the one-electron reduction or oxidation of $\mathrm{ABTS}^{+\bullet}$ (Figure $\left.2 \mathrm{a}\right)$. Non-phenolic and $N$-methyl betalains show lower TEAC compared to $m$-OH-pBeet, implying that both the phenolic group and the 1,7-diazaheptamethinium system are essential to explain the high radical scavenging capacity of betalains. Interestingly, the $m$-hydroxyl group had no effect on the TEAC of $N$-methyl betalains, possibly because the formation of iminoquinones is precluded due to the lack of conjugation between the hydroxyl group and the 1,7-diazaheptamethinium system.

Electrode potentials $\left(\mathrm{E}_{p} \mathrm{~s}\right)$ of pBeets and mepBeets were measured as a function of the $\mathrm{pH}$ to provide further insight into the effect of the structure of the betalain on its antiradical properties (Figure S10 and Figure 2b). $m-\mathrm{OH}$-pBeet and $m-\mathrm{OH}$-mepBeet are oxidized at an anodic potential $\left(\mathrm{E}_{p a}\right)$ around $700 \mathrm{mV}$ vs. $\mathrm{Ag} / \mathrm{AgCl}$, whereas the oxidation of pBeet requires a slightly higher potential (roughly $\mathrm{E}_{p a} \sim 900 \mathrm{mV}$ vs. $\mathrm{Ag} / \mathrm{AgCl}$ ). In both cases, the proton to electron ratio calculated from Nernst plots is one (Figure $2 b$ ), which is compatible with the oxidation of $(i)$ the phenol portion to the semiquinone $\left(-1 \mathrm{H}^{+} /-1 \mathrm{e}^{-}\right)$, (ii) the 1,7-diazaheptamethinium system to the corresponding radical cation $\left(-1 \mathrm{H}^{+} /-1 \mathrm{e}^{-}\right)$, and (iii) the 2-piperideine ring into 2,6-dicarboxy pyridine $\left(-2 \mathrm{H}^{+} /-2 \mathrm{e}^{-}\right)[54,55]$. The phenol and 1,7-diazaheptamethinium portions of $m-\mathrm{OH}$-pBeet and $m-\mathrm{OH}$-mepBeet are not conjugated and, therefore, are expected to scavenge radicals independently, without the formation of iminoquinones by $2 \mathrm{e}^{-}$-oxidation.

\subsection{Mechanisms of Radical Scavenging by Betalains}

Theoretical calculations provide in-depth insight into the mechanism of the antiradical action of betalains. Proton-coupled electron transfer (PCET) includes all processes involving electron/proton transfer [38,56]. Hydrogen atom transfer (HAT) and concerted proton-electron transfer (CPET) are examples of concerted PCET pathways [56]. Stepwise PCET occurs through sequential proton loss electron transfer (SPLET) or electron transfer followed by proton transfer (ET-PT). These concurrent reaction pathways can be represented using More O'Ferrall-Jencks (or 'square') diagrams and the thermodynamic preference of a given transformation can be inferred from experimental and theoretical parameters (Figure 3a).

The homolytic bond dissociation enthalpies (BDE) of N1-H, N9-H and/or ArO- $H$ bonds in all betalains are much lower than their adiabatic ionization potentials (IP) (Table 2). Consequently, the oxidation of betalains is likely to occur via either SPLET or HAT/CPET instead of by ET-PT. Kinetic and/or computational analysis is required to discriminate between HAT/CPET or SPLET mechanisms for the oxidation of betalains in water because the differences between their electron transfer enthalpies (ETE) and BDEs are lower than ca. $50 \mathrm{~kJ} \mathrm{~mol}^{-1}\left(12 \mathrm{kcal} \mathrm{mol}^{-1}\right)$, independent of the site of deprotonation (Table 2) [57-60]. The lowest energy pathway for the $1 \mathrm{H}^{+} / 1 \mathrm{e}^{-}$-oxidation of each betalain is shown in Figure 3b. For $m-\mathrm{OH}-\mathrm{pBeet}$ and pBeet, concerted PCET involving the N9-H moiety (N9 form, Figure $3 \mathrm{c}$ ) is preferred over the $\mathrm{N} 1-H$ (N1 form) and the phenol (ArO form), when feasible. 

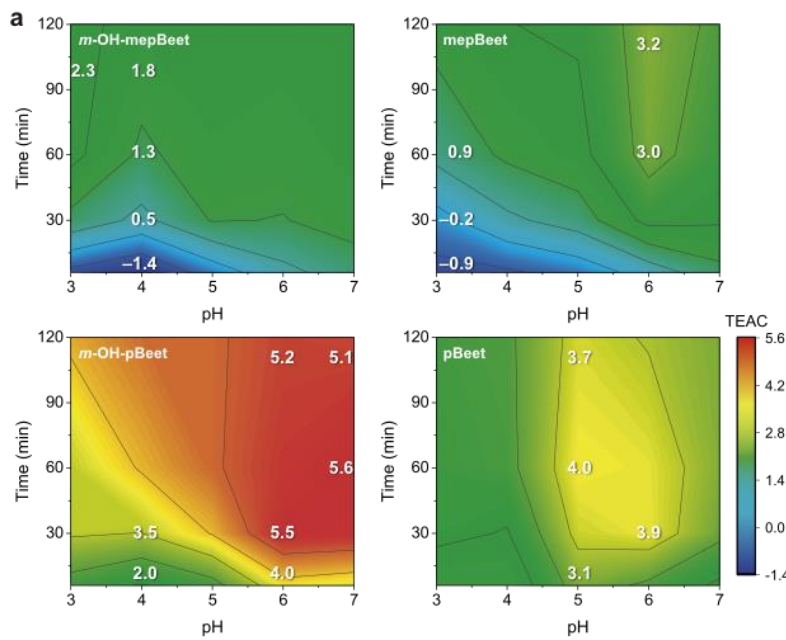

b
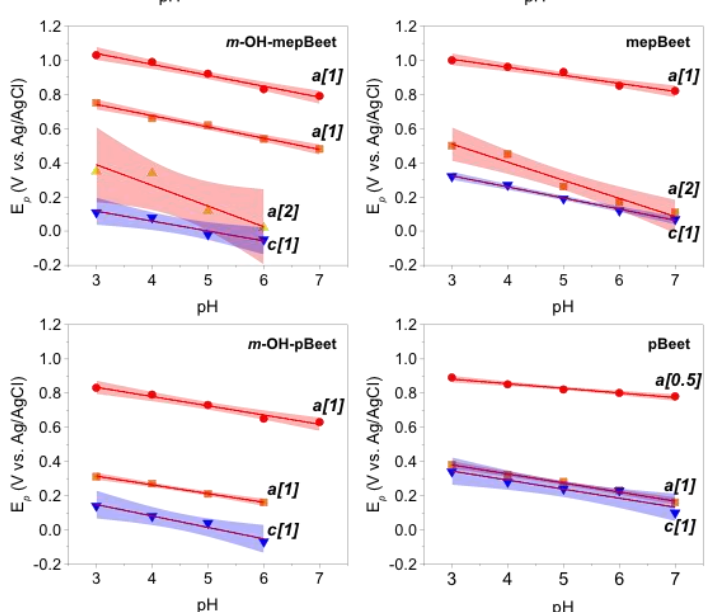

Figure 2. Antiradical capacity and redox properties of pBeet, mepBeet, $m-\mathrm{OH}-\mathrm{pBeet}$ and $m$-OH-mepBeet. (a) Colored contour map of Trolox equivalent antioxidant capacity (TEAC) of the betalains as a function of the $\mathrm{pH}$ ( $x$-axis) and reaction time ( $y$-axis). Red to blue color gradient indicating high to low (5.6 to -1.4) TEAC; selected TEAC contour values are indicated on the surface for clarity. Raw data is presented in Table S1. Reaction conditions: Britton-Robinson (BR) buffer $\left(40 \mathrm{mmol} \mathrm{L}^{-1}\right),\left[\mathrm{ABTS}^{+\bullet}\right]=$ $46.7 \mu \mathrm{mol} \mathrm{L}-1$, [Trolox]: $0.5-4 \mu \mathrm{mol} \mathrm{L}^{-1}$, [betalain]: $0.3-1.5 \mu \mathrm{mol} \mathrm{L}^{-1}$, at $25 \pm 1{ }^{\circ} \mathrm{C}$. (b) Dependence of the electrode potential $\left(\mathrm{E}_{p}\right)$ of the betalains on the $\mathrm{pH}$ (BR buffer). Straight lines show linear regressions (confidence interval of $95 \%$, red for anodic and blue for cathodic peaks); numbers in brackets are the proton to electron ratio. Cyclic voltammograms are presented in Figure S10.

The occurrence of concerted PCET (HAT or CPET mechanisms) can be inferred from the degree of thermodynamic coupling between the $\mathrm{p} K_{\mathrm{a}}$ and the $E^{\mathrm{o}}$. [38,61]. Unfortunately, the titration of betalains is difficult due to their rather limited solubility in water $\left(\leq 10 \mathrm{mmol} \mathrm{L}^{-1}\right)$, and fast hydrolysis and/or decomposition under very acidic or alkaline conditions $[16,50,51,62,63]$. Furthermore, anodic processes of pBeets and mepBeets are usually irreversible, making the calculation of formal redox potentials difficult (Figure S10). Therefore, to determine whether the oxidation of betalains occurs through HAT/CPET or SPLET, we calculated the change in the BDE using the isodesmic reaction between phenoxyl radical/phenol $(\mathrm{PhO} \bullet / \mathrm{PhOH}$ ) and betalains (Figure 3c). Changes in enthalpy for the reaction of either pBeet or $m-\mathrm{OH}$-pBeet with the phenoxyl radical are negative when the hydrogen atom attached to N9 is transferred. For $\mathrm{N}$-methyl betalains, however, the process is endothermic, independent of the deprotonation site, i.e., N1-H or ArO- $H$ (Table 2). From these results, we infer that changes in the acidity of $\mathrm{N} 1-H$ and $\mathrm{N} 9-H$ and the $E^{\mathrm{o}}$ are strongly related, indicating that HAT/CPET is the preferred thermodynamic pathway for the $1 \mathrm{e}^{-}$-oxidation of betalains. 

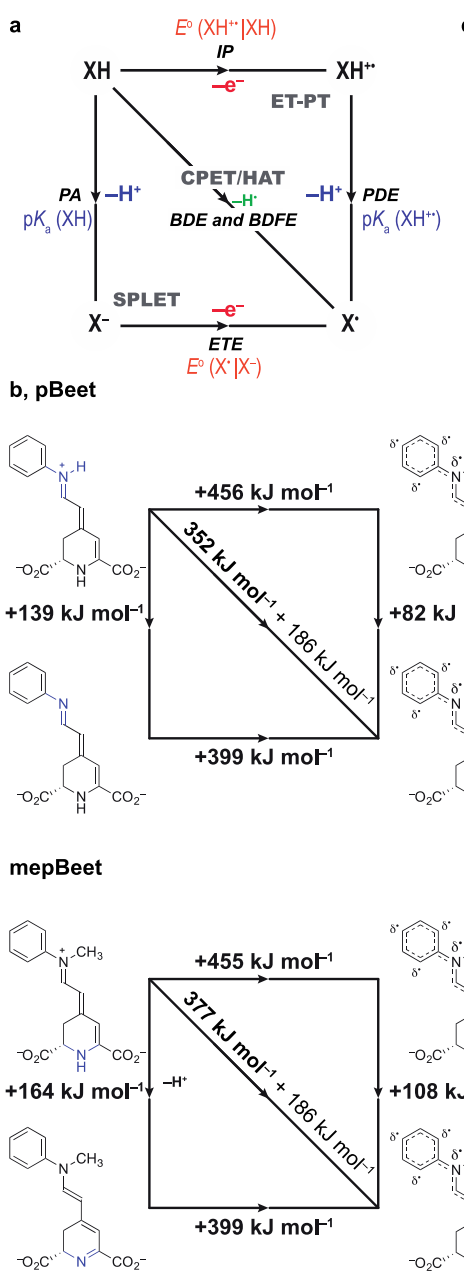
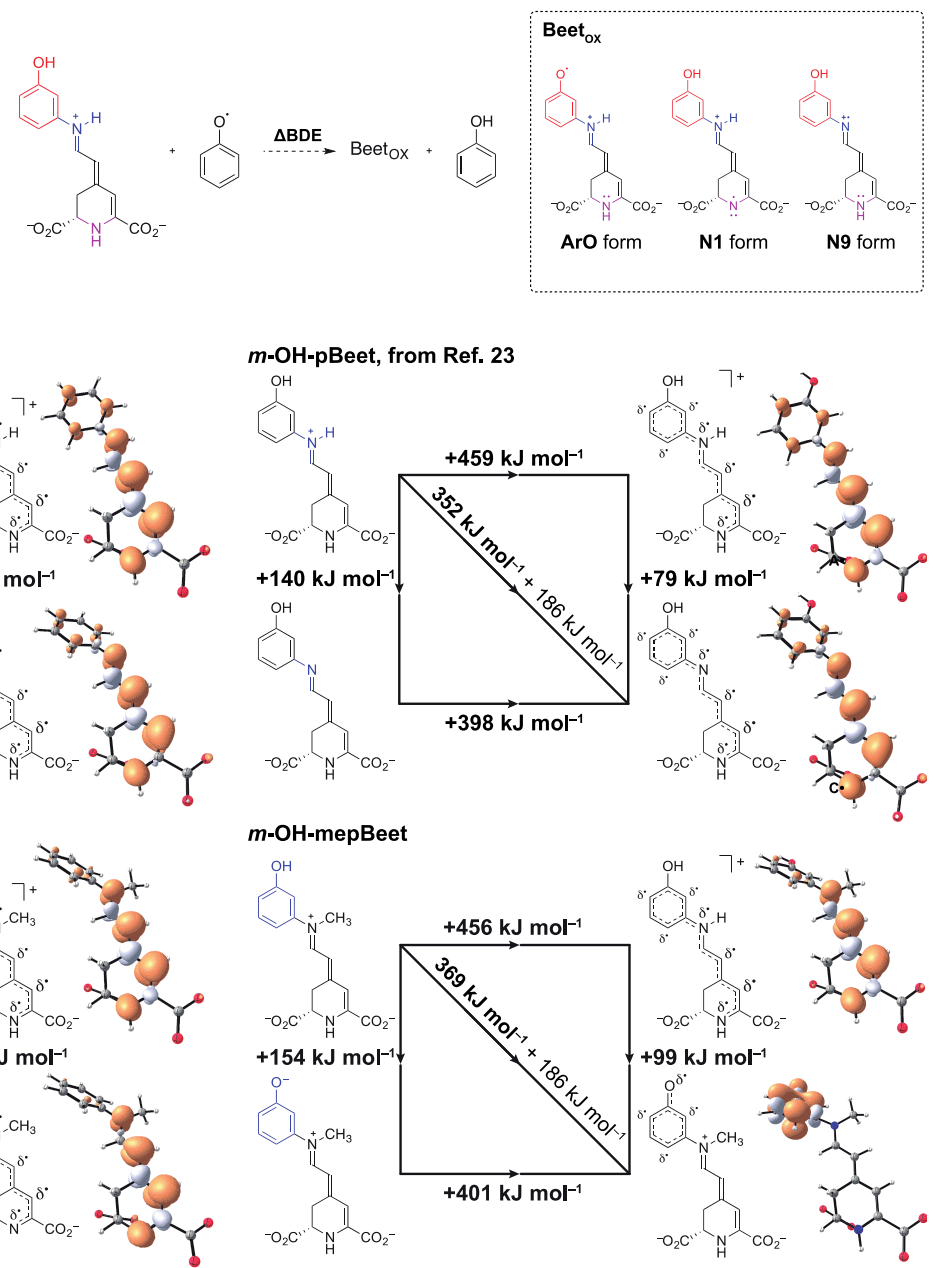

Figure 3. Mechanism of betanin oxidation. (a) More O'Ferrall-Jencks diagrams showing concurrent PCET processes of a generic compound $\mathrm{XH}[64,65]$, and the parameters that can be used for mechanistic interpretation, i.e. $\mathrm{p} K_{\mathrm{a}} \mathrm{s}$, reduction potentials $\left(E^{\mathrm{o}}\right)$, proton affinity $(\mathrm{PA})$, proton dissociation energy (PDE), ionization potential (IP), electron transfer enthalpy (ETE), and homolytic bond dissociation enthalpy (BDE). (b) More O'Ferrall-Jencks diagrams for the ionization and $1 \mathrm{e}^{-}$-oxidation of pBeet, $m$-OH-pBeet, mepBeet, and $m-\mathrm{OH}-\mathrm{mepBeet}$ to produce the lowest energy radical/radical-cation; compounds are presented as dicarboxylates since this is the expected major form in water at $\mathrm{pH}$ higher than $4[50,51]$. Energies refer to the enthalpy changes between states. Spin density distribution (isocontour $=0.004$ a.u., positive/orange and negative/white) and chemical structures show the delocalization of the unpaired electron. (c) Isodesmic reaction between the phenoxyl radical and betalains to produce phenol and the oxidized betalain (Beet $O x$ ). The designation of each betalain according to the site of deprotonation/oxidation of $m-\mathrm{OH}$-pBeet is presented for clarity and used in Table 2.

The analysis of the spin density distribution of the lowest energy $1 \mathrm{H}^{+} / 1 \mathrm{e}^{-}$-oxidized betalain revealed that the phenoxyl radical of $m$-OH-mepBeet is not delocalized over the 1,7-diazaheptamethinium system (Figure 2b). Conversely, for mepBeet, the spin density is almost fully located on the 1,7-diazaheptamethinium system after $1 \mathrm{e}^{-}$-oxidation and loss of the proton attached to N1. These results confirm the importance of both moieties for the overall radical scavenging capacity of betalains and indicate that they do not have to be conjugated. For betanin, the 5-O-glucosylated hydroxyl group of the cyclo-DOPA ((S)-2-carboxy-5,6-dihydroxyindoline) moiety is conjugated to the 1,7-diazaheptamethinium portion, but the 6-OH group is not, pointing to multiple sites of oxidation and supporting the hypothesis of PCET-mediated hole stabilization by betanin in nano-hybrid plasmonic systems for hydrogen production [19]. 
Table 2. Thermodynamic parameters of pBeets and mepBeets for the three most common radical scavenging mechanisms. ${ }^{\text {a. }}$

\begin{tabular}{ccccccc}
\hline \multirow{2}{*}{ Species $^{\mathbf{b}}$} & \multicolumn{2}{c}{ ET-PT } & HAT/PCET & \multicolumn{2}{c}{ SPLET } & PhO $\rightarrow$ PhOH \\
\cline { 2 - 7 } & IP & PDE & BDE & PA & ETE & $\Delta$ BDE $^{\text {PhOH }}$ \\
\hline pBeet & 456 & & & & & \\
N9 & & 82 & 352 & 139 & 399 & -11 \\
N1 & & 110 & 380 & 161 & 405 & 17 \\
\hline mepBeet & 455 & & & & & \\
N1 & & 108 & 377 & 164 & 399 & 14 \\
\hline$m$-OH-pBeet ${ }^{c}$ & 459 & & & & & \\
N9 & & 79 & 352 & 140 & 398 & -12 \\
ArO & & 96 & 369 & 154 & 401 & 5 \\
N1 & & 109 & 382 & 162 & 406 & 18 \\
\hline$m$-OH-mepBeet & 456 & & & & & \\
ArO & & 99 & 369 & 154 & 401 & 6 \\
N1 & & 108 & 378 & 164 & 400 & 15
\end{tabular}

${ }^{\text {a }}$ Values (in kJ mol${ }^{-1}$ ) were calculated using Equations (1)-(6), see Methods. ${ }^{\mathrm{b}}$ Species refer to the parent species and the deprotonation site (Figure 3c). ${ }^{c}$ from Reference [27].

\section{Conclusions}

$m$-OH-pBeet, a model compound for the antioxidant action of betalains, has three potential sites for PCET: the phenol moiety, the 1,7-diazaheptamethinium system and the 2-piperideine ring. For $m-\mathrm{OH}$-mepBeet, the presence of a methyl group attached to the N9 makes the oxidation of the 1,7-diazaheptamethinium system less favorable, lowers its radical scavenging capacity compared to $m$-OH-pBeet and promotes pro-oxidant action under acidic conditions. The deprotonation of the $\mathrm{N} 1-\mathrm{H}$ is the only pathway for the oxidation of the 1,7-diazaheptamethinium system of $m$-OH-mepBeet, but the resulting radical ion is not susceptible to further oxidation. Since pBeet performs much better than $m$-OH-mepBeet at near neutral conditions, the 1,7-diazaheptamethinium system is clearly more important for the overall radical scavenging capacity of betalains than the phenolic $m$-hydroxyl moiety. Concerted PCET involving the proton at N9-H of the 1,7-diazaheptamethinium system is the thermodynamically most favorable mechanism for the oxidation of $m-\mathrm{OH}$-pBeet and pBeet, while for mepBeet and $\mathrm{m}-\mathrm{OH}-m e p B e e t$ the preferred pathways are the less spontaneous oxidation of the 1,7-diazaheptamethinium system via the $\mathrm{N} 1$ proton and the phenol, respectively. The present results thus demonstrate that the 1,7-diazaheptamethinium moiety is the key structural feature responsible for the efficient concerted PCET radical scavenging capacity of betalains even in the absence of conjugation to a phenol moiety.

Supplementary Materials: The following are available online at http://www.mdpi.com/2076-3921/8/7/222/s1, Supplementary Methods, Figure S1: ${ }^{1} \mathrm{H}$ NMR spectrum $\left(500 \mathrm{MHz}, \mathrm{CD}_{3} \mathrm{OD}\right)$ of pBeet, Figure S2: ESI(+)-MS spectrum of pBeet, Figure S3: ${ }^{1} \mathrm{H}$ NMR spectrum $\left(500 \mathrm{MHz}, \mathrm{CD}_{3} \mathrm{OD}\right)$ of mepBeet, Figure S4: ESI(+)-MS spectrum of mepBeet, Figure S5: ${ }^{1} \mathrm{H}$ NMR spectrum $\left(500 \mathrm{MHz}, \mathrm{CD}_{3} \mathrm{OD}\right)$ of $m-\mathrm{OH}-\mathrm{pBeet}$, Figure S6: ESI(+)-MS spectrum of m-OH-pBeet, Figure S7: ${ }^{1} \mathrm{H}$ NMR spectrum $\left(500 \mathrm{MHz}, \mathrm{CD}_{3} \mathrm{OD}\right.$ ) of $m$-OH-mepBeet, Figure S8: ESI(+)-MS spectrum of $m$-OH-mepBeet, Figure S9: Normalized absorption spectra of pBeets, mepBeets and ABTS ${ }^{+\bullet}$, Figure S10: Cyclic voltammograms of pBeets and mepBeets in BR buffer at $\mathrm{pH}$ ranging from 3 to 7 , Figure S11: UV-Vis spectra of pBeet, mepBeet, $m$-OH-pBeet and $m$-OH-mepBeet over time, and Table S1: TEAC values \pm sd of the pBeets and the mepBeets.

Author Contributions: E.L.B. conceived the study and wrote the paper; E.L.B. and K.K.N. designed the experiments; K.K.N performed experimental work and E.L.B. carried out theoretical calculations. Both authors discussed and interpreted results.

Funding: This research was funded by the São Paulo Research Foundation-FAPESP (ELB, 2014/22136-4, 2016/21445-9 and 2019/06391-8; KKN 2013/24964-9), the Brazilian National Council for Scientific and Technological Development-CNPq (ELB, 303341/2016-5), and the Coordenação de Aperfeiçoamento de Pessoal de Nivel Superior (CAPES, Finance Code 001). 
Acknowledgments: We thank Janaina D. Vilcachagua (Analytical Central, IQUSP) for help with the NMR analyses, Carla S. Santos and Alex Lima for their support during the acquisition of electrochemical data, and Ernani Pinto and Felipe Dörr for making the LC-MS facility available for us.

Conflicts of Interest: The authors declare no conflicts of interest.

\section{References}

1. Koppenol, W.H.; Hider, R.H. Iron and redox cycling. Do's and don'ts. Free Radic. Biol. Med. 2019, 133, 3-10. [CrossRef]

2. Apel, K.; Hirt, H. Reactive oxygen species: Metabolism, oxidative stress, and signal transduction. Annu. Rev. Plant Biol. 2004, 55, 373-399. [CrossRef] [PubMed]

3. Winterbourn, C.C. Reconciling the chemistry and biology of reactive oxygen species. Nat. Chem. Biol. 2008, 4, 278-286. [CrossRef] [PubMed]

4. Sies, H. Oxidative stress: A concept in redox biology and medicine. Redox Biol. 2015, 4, 180-183. [CrossRef] [PubMed]

5. Mittler, R. ROS Are Good. Trends Plant Sci. 2017, 22, 11-19. [CrossRef] [PubMed]

6. Herbert, V. The antioxidant supplement myth. Am. J. Clin. Nutr. 1994, 60, 157-158. [CrossRef]

7. Prior, R.L.; Cao, G. Analysis of botanicals and dietary supplements for antioxidant capacity: A review. J. AOAC Int. 2000, 83, 950-956.

8. Frei, B. Reactive oxygen species and antioxidant vitamins: Mechanisms of action. Am. J. Med. 1994, 97, S5-S13. [CrossRef]

9. Salehi, B.; Martorell, M.; Arbiser, J.L.; Sureda, A.; Martins, N.; Maurya, P.K.; Sharifi-Rad, M.; Kumar, P.; Sharifi-Rad, J. Antioxidants: Positive or Negative Actors? Biomolecules 2018, 8, 124. [CrossRef]

10. Rietjens, I.M.; Boersma, M.G.; Haan, L.; Spenkelink, B.; Awad, H.M.; Cnubben, N.H.; van Zanden, J.J.; Woude, H.; Alink, G.M.; Koeman, J.H. The pro-oxidant chemistry of the natural antioxidants vitamin C, vitamin E, carotenoids and flavonoids. Environ. Toxicol. Pharmacol. 2002, 11, 321-333. [CrossRef]

11. Graham, H.N. Green tea composition, consumption, and polyphenol chemistry. Prev. Med. 1992, 21, 334-350. [CrossRef]

12. Polturak, G.; Aharoni, A. "La vie en rose": Biosynthesis, sources, and applications of betalain pigments. Mol. Plant 2018, 11, 7-22. [CrossRef] [PubMed]

13. Davies, K.M. Swapping one red pigment for another. Nat. Genet. 2015, 47, 5-6. [CrossRef] [PubMed]

14. Osbourn, A. Painting with betalains. Nat. Plants 2017, 3, 852-853. [CrossRef] [PubMed]

15. Quina, F.H.; Bastos, E.L. Chemistry Inspired by the Colors of Fruits, Flowers and Wine. An. Acad. Bras. Cienc. 2018, 90, 681-695. [CrossRef] [PubMed]

16. Esteves, L.C.; Pinheiro, A.C.; Pioli, R.M.; Penna, T.C.; Baader, W.J.; Correra, T.C.; Bastos, E.L. Revisiting the mechanism of hydrolysis of betanin. Photochem. Photobiol. 2018, 94, 853-864. [CrossRef]

17. Treat, N.A.; Knorr, F.J.; McHale, J.L. Templated assembly of betanin chromophore on TiO2: Aggregation-enhanced light-harvesting and efficient electron injection in a natural dye-sensitized solar cell. J. Phys. Chem. C 2016, 120, 9122-9131. [CrossRef]

18. Pavliuk, M.V.; Cieslak, A.M.; Abdellah, M.; Budinska, A.; Pullen, S.; Sokolowski, K.; Fernandes, D.L.A.; Szlachetko, J.; Bastos, E.L.; Ott, S.; et al. Hydrogen evolution with nanoengineered ZnO interfaces decorated using a beetroot extract and a hydrogenase mimic. Sustain. Energy Fuels 2017, 1, 69-73. [CrossRef]

19. Pavliuk, M.V.; Fernandes, A.B.; Abdellah, M.; Fernandes, D.L.A.; Machado, C.O.; Rocha, I.; Hattori, Y.; Paun, C.; Bastos, E.L.; Sa, J. Nano-hybrid plasmonic photocatalyst for hydrogen production at $20 \%$ efficiency. Sci. Rep. 2017, 7, 8670. [CrossRef]

20. Fernandes, D.L.A.; Paun, C.; Pavliuk, M.V.; Fernandes, A.B.; Bastos, E.L.; Sa, J. Green microfluidic synthesis of monodisperse silver nanoparticles via genetic algorithm optimization. RSC Adv. 2016, 6, 95693-95697. [CrossRef]

21. Martinez, R.M.; Longhi-Balbinot, D.T.; Zarpelon, A.C.; Staurengo-Ferrari, L.; Baracat, M.M.; Georgetti, S.R.; Sassonia, R.C.; Verri, W.A.; Casagrande, R. Anti-inflammatory activity of betalain-rich dye of Beta vulgaris: Effect on edema, leukocyte recruitment, superoxide anion and cytokine production. Arch. Pharm. Res. 2015, 38, 494-504. [CrossRef] [PubMed] 
22. Esatbeyoglu, T.; Wagner, A.E.; Schini-Kerth, V.B.; Rimbach, G. Betanin-A food colorant with biological activity. Mol. Nutr. Food Res. 2015, 59, 36-47. [CrossRef] [PubMed]

23. Parikh, I.; Hilpert, H.; Hermann, K.; Dreiding, A.S. Synthese von Betenamin und von Betalain-Modellsubstanzen. Helv. Chim. Acta 1986, 69, 1588-1596. [CrossRef]

24. Khan, M.I. Plant betalains: Safety, antioxidant activity, clinical efficacy, and bioavailability. Compr. Rev. Food Sci. Food Saf. 2016, 15, 316-330. [CrossRef]

25. Gliszczyńska-Świgło, A.; Szymusiak, H.; Malinowska, P. Betanin, the main pigment of red beet: Molecular origin of its exceptionally high free radical-scavenging activity. Food Addit. Contam. A 2006, 23, 1079-1087. [CrossRef]

26. Albano, C.; Negro, C.; Tommasi, N.; Gerardi, C.; Mita, G.; Miceli, A.; De Bellis, L.; Blando, F. Betalains, Phenols and Antioxidant Capacity in Cactus Pear [Opuntia ficus-indica (L.) Mill.] Fruits from Apulia (South Italy) Genotypes. Antioxidants 2015, 4, 269-280. [CrossRef]

27. Gonçalves, L.C.P.; Lopes, N.B.; Augusto, F.A.; Pioli, R.M.; Machado, C.O.; Freitas-Dörr, B.C.; Suffredini, H.B.; Bastos, E.L. Phenolic betalain as antioxidants: Meta means more. Pure Appl. Chem. 2019, in press. [CrossRef]

28. Schliemann, W.; Kobayashi, N.; Strack, D. The decisive step in betaxanthin biosynthesis is a spontaneous reaction. Plant Physiol. 1999, 119, 1217-1232. [CrossRef]

29. Re, R.; Pellegrini, N.; Proteggente, A.; Pannala, A.; Yang, M.; Rice-Evans, C. Antioxidant activity applying an improved ABTS radical cation decolorization assay. Free Radic. Biol. Med. 1999, 26, 1231-1237. [CrossRef]

30. Dunning, T.H. Gaussian basis sets for use in correlated molecular calculations. I. The atoms boron through neon and hydrogen. J. Chem. Phys. 1989, 90, 1007-1023. [CrossRef]

31. Zhao, Y.; Truhlar, D.G. The M06 suite of density functionals for main group thermochemistry, thermochemical kinetics, noncovalent interactions, excited states, and transition elements: Two new functionals and systematic testing of four M06-class functionals and 12 other functionals. Theor. Chem. Acc. 2008, 120, 215-241. [CrossRef]

32. Dimić, D.; Milenković, D.; Dimitrić Marković, J.; Marković, Z. Antiradical activity of catecholamines and metabolites of dopamine: Theoretical and experimental study. PCCP 2017, 19, 12970-12980. [CrossRef] [PubMed]

33. Frisch, M.J.; Trucks, G.W.; Schlegel, H.B.; Scuseria, G.E.; Robb, M.A.; Cheeseman, J.R.; Scalmani, G.; Barone, V.; Mennucci, B.; Petersson, G.A.; et al. Gaussian 09, Revision D.01; Gaussian, Inc.: Wallingford, CT, USA, 2009; citeulike-article-id:9096580.

34. Marković, Z.; Đorović, J.; Petrović, Z.D.; Petrović, V.P.; Simijonović, D. Investigation of the antioxidant and radical scavenging activities of some phenolic Schiff bases with different free radicals. J. Mol. Model. 2015, 21, 293. [CrossRef] [PubMed]

35. Szelag, M.; Urbaniak, A.; Bluyssen Hans, A.R. A theoretical antioxidant pharmacophore for natural hydroxycinnamic acids. Open Chem. 2015, 13, 17-31. [CrossRef]

36. Marković, Z.; Tošović, J.; Milenković, D.; Marković, S. Revisiting the solvation enthalpies and free energies of the proton and electron in various solvents. Comput. Theor. Chem. 2016, 1077, 11-17. [CrossRef]

37. Petrović, Z.D.; Đorović, J.; Simijonović, D.; Petrović, V.P.; Marković, Z. Experimental and theoretical study of antioxidative properties of some salicylaldehyde and vanillic Schiff bases. RSC Adv. 2015, 5, 24094-24100. [CrossRef]

38. Warren, J.J.; Tronic, T.A.; Mayer, J.M. Thermochemistry of proton-coupled electron transfer reagents and its implications. Chem. Rev. 2010, 110, 6961-7001. [CrossRef] [PubMed]

39. Byrne, F.P.; Jin, S.; Paggiola, G.; Petchey, T.H.M.; Clark, J.H.; Farmer, T.J.; Hunt, A.J.; Robert McElroy, C.; Sherwood, J. Tools and techniques for solvent selection: Green solvent selection guides. Sustain. Chem. Proc. 2016, 4, 7-31. [CrossRef]

40. Kimler, L.; Larson, R.A.; Messenger, L.; Moore, J.B.; Mabry, T.J. Betalamic acid, a new naturally occurring pigment. J. Chem. Soc. D Chem. Commun. 1971, 1329-1330. [CrossRef]

41. Gandia-Herrero, F.; Escribano, J.; Garcia-Carmona, F. Structural implications on color, fluorescence, and antiradical activity in betalains. Planta 2010, 232, 449-460. [CrossRef]

42. Gandia-Herrero, F.; Escribano, J.; Garcia-Carmona, F. Betaxanthins as pigments responsible for visible fluorescence in flowers. Planta 2005, 222, 586-593. [CrossRef] [PubMed] 
43. Bartoloni, F.H.; Goncalves, L.C.P.; Rodrigues, A.C.B.; Dorr, F.A.; Pinto, E.; Bastos, E.L. Photophysics and hydrolytic stability of betalains in aqueous trifluoroethanol. Monatsh. Chem. 2013, 144, 567-571. [CrossRef]

44. Wendel, M.; Nizinski, S.; Tuwalska, D.; Starzak, K.; Szot, D.; Prukala, D.; Sikorski, M.; Wybraniec, S.; Burdzinski, G. Time-resolved spectroscopy of the singlet excited state of betanin in aqueous and alcoholic solutions. PCCP 2015, 17, 18152-18158. [CrossRef] [PubMed]

45. Wendel, M.; Szot, D.; Starzak, K.; Tuwalska, D.; Gapinski, J.; Naskrecki, R.; Prukala, D.; Sikorski, M.; Wybraniec, S.; Burdzinski, G. Photophysical properties of betaxanthins: Vulgaxanthin I in aqueous and alcoholic solutions. J. Luminesc. 2015, 167, 289-295. [CrossRef]

46. Alabugin, I.V.; Gilmore, K.M.; Peterson, P.W. Hyperconjugation. Wiley Interd. Rev. Comput. Mol. Sci. 2011, 1, 109-141. [CrossRef]

47. Gonçalves, L.C.P.; Di Genova, B.M.; Dörr, F.A.; Pinto, E.; Bastos, E.L. Effect of dielectric microwave heating on color and antiradical capacity of betanin. J. Food Eng. 2013, 118, 49-55. [CrossRef]

48. Gonçalves, L.C.P.; Da Silva, S.M.; DeRose, P.; Ando, R.A.; Bastos, E.L. Beetroot-pigment-derived colorimetric sensor for detection of calcium dipicolinate in bacterial spores. PLoS ONE 2013, 8, e73701. [CrossRef]

49. Gonçalves, L.C.P.; Tonelli, R.R.; Bagnaresi, P.; Mortara, R.A.; Ferreira, A.G.; Bastos, E.L. A nature-inspired betalainic probe for live-cell imaging of Plasmodium-infected erythrocytes. PLoS ONE 2013, 8, e53874. [CrossRef]

50. Nilsson, T. Studies into the pigments in beetroot (Beta vulgaris L. ssp. vulgaris var. rubra L.). Lantbr. Högsk. Annlr. 1970, 36, 179-219.

51. Piattelli, M.; Minale, L.; Prota, G. Isolation, structure and absolute configuration of indicaxanthin. Tetrahedron 1964, 20, 2325-2329. [CrossRef]

52. Karstens, T.; Kobs, K. Rhodamine-B and rhodamine-101 as reference substances for fluorescence quantum yield measurements. J. Phys. Chem. 1980, 84, 1871-1872. [CrossRef]

53. Schaich, K.M.; Tian, X.; Xie, J. Hurdles and pitfalls in measuring antioxidant efficacy: A critical evaluation of ABTS, DPPH, and ORAC assays. J. Funct. Foods 2015, 14, 111-125. [CrossRef]

54. Wybraniec, S.; Michalowski, T. New pathways of betanidin and betanin enzymatic oxidation. J. Agric. Food Chem. 2011, 59, 9612-9622. [CrossRef] [PubMed]

55. Wybraniec, S.; Starzak, K.; Skopinska, A.; Nemzer, B.; Pietrzkowski, Z.; Michalowski, T. Studies on nonenzymatic oxidation mechanisms in neobetanin, betanin, and decarboxylated betanins. J. Agric. Food Chem. 2013, 61, 6465-6476. [CrossRef] [PubMed]

56. Darcy, J.W.; Koronkiewicz, B.; Parada, G.A.; Mayer, J.M. A continuum of proton-coupled electron transfer reactivity. Acc. Chem. Res. 2018, 51, 2391-2399. [CrossRef] [PubMed]

57. Huang, D.; Ou, B.; Prior, R.L. The chemistry behind antioxidant capacity assays. J. Agric. Food Chem. 2005, 53, 1841-1856. [CrossRef]

58. Tishchenko, O.; Truhlar, D.G.; Ceulemans, A.; Nguyen, M.T. A unified perspective on the hydrogen atom transfer and proton-coupled electron transfer mechanisms in terms of topographic features of the ground and excited potential energy surfaces as exemplified by the reaction between phenol and radicals. J. Am. Chem. Soc. 2008, 130, 7000-7010. [CrossRef] [PubMed]

59. Weinberg, D.R.; Gagliardi, C.J.; Hull, J.F.; Murphy, C.F.; Kent, C.A.; Westlake, B.C.; Paul, A.; Ess, D.H.; McCafferty, D.G.; Meyer, T.J. Proton-coupled electron transfer. Chem. Rev. 2012, 112, 4016-4093. [CrossRef]

60. Tian, X.; Schaich, K.M. Effects of molecular structure on kinetics and dynamics of the trolox equivalent antioxidant capacity assay with ABTS+•. J. Agric. Food Chem. 2013, 61, 5511-5519. [CrossRef]

61. Bordwell, F.G.; Cheng, J.P.; Harrelson, J.A. Homolytic bond dissociation energies in solution from equilibrium acidity and electrochemical data. J. Am. Chem. Soc. 1988, 110, 1229-1231. [CrossRef]

62. Reznik, H. Die pigmente der centrospermen als systematisches element. Planta 1957, 49, 406-434. [CrossRef]

63. Gandia-Herrero, F.; Escribano, J.; Garcia-Carmona, F. Purification and antiradical properties of the structural unit of betalains. J. Nat. Prod. 2012, 75, 1030-1036. [CrossRef] [PubMed] 
64. Leopoldini, M.; Marino, T.; Russo, N.; Toscano, M. Antioxidant properties of phenolic compounds: H-atom versus electron transfer mechanism. J. Phys. Chem. A 2004, 108, 4916-4922. [CrossRef]

65. Apak, R. Electron transfer-based antioxidant capacity assays and the cupric ion reducing antioxidant capacity (CUPRAC) assay. In Measurement of Antioxidant Activity \& Capacity: Recent Trends and Applications; John Wiley \& Sons Ltd: Chichester, UK, 2018; pp. 57-75.

(c) (

(C) 2019 by the authors. Licensee MDPI, Basel, Switzerland. This article is an open access article distributed under the terms and conditions of the Creative Commons Attribution (CC BY) license (http://creativecommons.org/licenses/by/4.0/). 